\title{
BIPOLAR DISORDER AND MULTIPLE SCLEROSIS
}

\author{
Mariana Inés Ybarra', Marcos Aurélio Moreira², Carolina Reis Araújo33, \\ Marco Aurélio Lana-Peixoto ${ }^{4}$, Antonio Lucio Teixeira ${ }^{5}$
}

\begin{abstract}
Bipolar disorder may be overrepresented in multiple sclerosis (MS) patients. Although research in this area is limited, studies assessing the nature of this association have focused on genetic aspects, adverse reaction to drugs and brain demyelinating lesions. Herein we report three patients with MS that also presented bipolar disorder. The coexistence of neurological and psychiatric symptoms in most MS relapses highlights the relevance of biological factors in the emergence of mood disorders in these patients.
\end{abstract}

KEY WORDS: multiple sclerosis, bipolar disorder.

\begin{abstract}
Transtorno bipolar e esclerose múltipla
RESUMO - O transtorno bipolar do humor parece estar super-representado em pacientes com esclerose múltipla (EM). Apesar de a pesquisa nessa área ser limitada, estudos acerca da natureza dessa associação têm se concentrado em aspectos genéticos, reações adversas a drogas e lesões desmielinizantes no sistema nervoso central. Relatamos, aqui, três casos de pacientes com EM que também apresentaram transtorno bipolar do humor. A coexistência de sintomas neurológicos e psiquiátricos em grande parte das recaídas de EM reforça a importância de fatores biológicos na gênese dos sintomas afetivos nesses pacientes.
\end{abstract}

PALAVRAS-CHAVE: esclerose múltipla, transtorno bipolar.

Multiple sclerosis (MS) is a chronic neurological disease characterized by a demyelinating process in the central nervous system and is the most common cause of neurological disability in young and middle aged adults'. The presence of psychiatric symptoms in MS is known since the first clinical descriptions of the disease in the early $19^{\text {th }}$ century. Nevertheless, it was only in the last two decades that more detailed studies were carried out.

Bipolar disorder (BD) is a psychiatric condition in which depressed mood alternates with manic episodes. It has an estimated prevalence of $1 \%$ worldwide $^{2}$. Mania in association with multiple sclerosis seems to occur more frequently than chance expectation and may, in some patients, be a presenting symptom of the disease ${ }^{3}$. An important evidence of this association came from a study by Schiffer et al. ${ }^{4}$, who attempted to trace all patients with both $B D$ and MS out of a population of 702.238 inhabitants of Monroe County, New York. As these authors assumed a lifetime risk of $0.77 \%$ for BD and a prevalence of 100:100.000 for MS, the estimate rate of comorbidity was 5.4 patients. Nevertheless, they found a number of patients with both conditions two times higher. Other studies have also suggested that the lifetime prevalence of BD seems to be more common in MS patients than in the general population ${ }^{5,6}$. According to these studies, this higher comorbidity seems to involve a diversity of factors such as steroid treatment, demyelinating lesions, genetics and family history of psychiatric disorders.

Herein we present three cases of MS with comorbid BD according to DSM-IV-TR diagnostic criteria. These cases highlight the clinical challenge of distinguishing between organic and functional affective illness in patients with MS.

\section{CASES}

Case 1-A 43 year-old woman was admitted to our clinic with an 18 month history of progressive spastic paraparesis and ataxia. Of note in her past medical history, she had been diagnosed with BD when she was 18 years old. At that time, she developed a major depressive disorder marked by sadness, apathy, social isolation and reduced appetite, followed in few months by a manic episode with expansive mood, grandiosity, hyperactivity and reduced need for sleep. She was treated with lithium carbonate and the

CIEM - Minas, Centro de Investigação em Esclerose Múltipla, Hospital das Clínicas da Universidade Federal de Minas Gerais, Belo Horizonte MG, Brasil (UFMG): 'Médica Psiquiatra; ${ }^{2}$ Médico Neurologista; ${ }^{3}$ Médica; ${ }^{4}$ Professor de Neurologia e Oftalmologia da Fa-

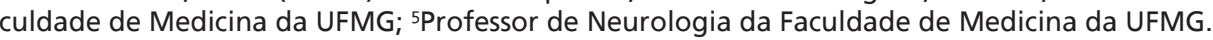

Received 29 March 2007, received in final form 10 August 2007. Accepted 6 September 2007.

Dr. Antonio Lucio Teixeira - Departamento de Clínica Médica / Faculdade de Medicina I UFMG - Avenida Alfredo Balena 190 - $30130-$ 100 Belo Horizonte MG - Brasil. E-mail: altexr@gmail.com 
mood symptoms remitted. On long term follow up, she evolved with mild to moderate mood swings never requiring psychiatric admission. At neurological consultation, she was using lithium and benzodiazepine with no significant affective symptoms.

She was submitted to a careful laboratory workup, including hemogram, ionogram, renal, thyroid and liver function tests, serological tests for HIV, HTLV, syphilis, and inflammatory tests, which were unrevealing. Brain and spine cord magnetic resonance imaging (MRI) displayed T2 hyperintense lesions in periventricular and semioval white matter. There were also gadolinium-enhanced lesions in periventricular white matter. The diagnosis of primary progressive MS was established. Pulse therapy with methylprednisolone was performed with no clinical improvement and no mood change was noticed after this treatment. On follow up, motor, sensory and sphincter symptoms deteriorated despite treatment with oral methotrexate.

Case 2 - The first MS symptoms of this male subject were paresthesias in lower limbs when he was 43 years old. Thereafter he had a series of seven relapses during the first five years of MS. He presented motor, cerebellar and sphincter symptoms despite treatment with beta-interferon. In most relapses, neurological symptoms were followed by fatigue and depressive mood. These psychiatric symptoms tended to resolve spontaneously as the relapses faded. He evolved with secondary MS at the seventh year of disease, displaying an Expanded Disability Status Scale (EDSS) of 6.5. He developed a sudden behavioral change marked by elated mood, irritability with increased motor activity and racing thoughts but no psychotic symptoms, i.e. delusion or hallucination. A careful laboratory workup was performed, but no alterations were found. MRI study of the brain revealed multiple ovoid and confluent T2 hyperintense lesions in periventricular and subcortical white matter, as well as in corpus callosum and medulla oblongata-cervical spine transition. There was also mild diffuse cortical atrophy. No gadolinium-enhanced lesions were noticed. A manic episode was diagnosed and the patient was treated with lithium carbonate. He evolved with remission of manic symptoms, but as he did not tolerate lithium, the drug was changed to valproic acid. On follow-up, he presented no more manic episodes but few depressive symptoms.

Case 3 - A 38 year-old woman presented with limb weakness followed by ataxia some months later. Diagnosed with MS she was given beta-interferon. During the first three years of disease, she had three episodes marked by optic neuritis and sphincter symptoms besides motor and sensory abnormalities. She also displayed significant depressive symptoms, such as sadness, apathy and fatigue, not related to MS relapses. After four years of MS diagnosis, she developed a frank manic episode marked by euphoria, increased activity, decreased need for sleep or rest and excessive talkativeness. This behavioral episode was not associated with new or deteriorating neurological symptoms indicative of MS relapse. MRI demonstrated multiple T2 hyperintense lesions in periventricular and subcortical, mainly in frontal and temporal lobes, cerebellum and pons. No gadolinium-enhanced lesions were identified. She was treated with lithium carbonate with adequate control of the symptoms. On follow-up she had other hypomanic episodes not related to MS relapses, which were controlled with benzodiazepines in addition to lithium.

\section{DISCUSSION}

The first case report describes a woman with a long term history of BD who developed MS. In this case, the most likely explanation for the comorbidity would be a casual association. MS is a relatively uncommon condition with an estimated prevalence of 15 cases per 100,000 inhabitants in Brazil, but BD affects approximately $1 \%$ of the population. As BD patients have at least the same risk of developing MS than non-BD subjects, it is possible to identify this association by chance at tertiary referral centers. An alternative explanation would be that the mood disorder was the presenting symptom of MS years before the development of neurological symptoms. Although much less likely, previous studies addressed this possibility. Hutchinson et al. 7 reported on seven MS patients with BD prior to the onset of MS. More recently, Asghar-Ali et al. ${ }^{8}$ reported two patients presenting manic and depressive symptoms who were diagnosed with MS without exhibiting any motor, sensory or autonomic symptoms during follow-up. These case reports highlight the view that psychiatric symptoms may be a presenting finding of MS and may occur in up to $1 \%$ of the patients ${ }^{9}$. Interestingly, psychotic disorders at onset were more frequently reported, while depressive and hypomanic episodes may go unnoticed in clinical practice ${ }^{9}$. The corollary of this assumption is that psychiatrists should include MS in their differential diagnosis.

The other two cases had emerging BD in previously diagnosed MS patients. In case 2, manic symptoms appeared in a patient with secondary progressive MS, while in case 3 manic and depressive episodes developed in a patient with relapsing-remitting MS. The interesting issues of both cases refer to the development of psychiatric symptoms in relation with neurological deficits and lesion location. Patient 2 developed frank mania with psychomotor agitation paralleling significant motor deterioration usually seen in secondary progressive MS. In such type of MS, neurological damage may occur and tends to persist without obvious inflammatory activity as evidenced by the presence of gadolinium-enhanced lesions. Therefore psychiatric symptoms probably emerged from the ongoing lesions on certain brain circuits involving mood regulation. In case 3 , the patient evolved with psy- 
chiatric symptoms not related with clinical relapse or disease activity. It seems plausible that mood swings also resulted from the impairment of brain circuits although this is not as evident as in the case 2. Another possibility would be a mood reaction to drugs, as previously suggested by some authors ${ }^{10}$. Behavioral adverse effects during systemic corticosteroid treatment seem to be common. Among patients without MS treated with corticosteroids, a large meta-analysis found that severe reactions occurred in nearly $6 \%$ of patients, and mild to moderate reactions occurred in about $28 \%^{10}$. The most commonly reported behavioral-induced disorders are affective, including mania, depression or mixed states" ${ }^{11}$. Patients receiving shortterm corticosteroid therapy tend to present with euphoria or hypomania, while long-term therapy tends to induce depressive symptoms ${ }^{12}$. Among MS patients treated with corticosteroids or ACTH, two systematic studies found that $40 \%$ of patients became depressed, 31\% hypomanic, $11 \%$ experienced both conditions and $16 \%$ psychotic ${ }^{13,14}$. ACTH appeared to be more potent than prednisone in inducing hypomania or mania. Of note, these symptoms did not occur with every drug exposure and subsided with discontinuation of the treatment.

Although highly debatable, beta-interferon might lead to affective symptoms, especially depressive ones in the beginning of the treatment ${ }^{15,16}$. Nevertheless, since patient 3 had no psychiatric symptoms during treatment with corticosteroids and had been using beta-interferon for a long time before the development of affective symptoms, a mood disorder secondary to drugs seems unlikely.

It is worth mentioning that unlike depression, which generally presents with anxious symptoms and irritability in MS patients, mania seems not to present with specific features in these patients ${ }^{1,8,9}$. Apart from neurological signs and symptoms, which may be present in MS patients, psychopathology regarding mania remains almost the same of non-MS subjects: excess of energy, talkativeness, psychomotor agitation, uninhibited behavior, sleeplessness, and impulsivity are mostly common.

At least three brain circuits involved in the control of human behavior emerge from the prefrontal cortex, known as dorsolateral, orbitofrontal and medial frontostriatal circuits. As axonal projections from these cortical areas course through the white matter to the basal ganglia, they may be damaged by MS demyelinating lesions. Since all cases presented with diffuse lesions in subcortical white matter, notably in frontal lobes, the disruption of these circuits could explain at least part of the symptoms observed. For instance, lesion of the orbitofrontal circuit, responsible for empathy and inhibition of socially inappropriate behavior, may lead to impulsivity and lability, features of manic episodes.

Neuroimaging studies on BD in patients without MS have tried to associate clinical findings to increased rate of white matter and periventricular hyperintensities ${ }^{17}$. There seems to be a complex relationship between these findings since hyperintensities have been associated to cerebrovascular disease but may also occur in asymptomatic elderly and in other clinical situations. For instance, Mc Donald et al. ${ }^{18}$ found a higher incidence of T2 hyperintensities in late-onset BD whereas Dupont et al. ${ }^{19}$ demonstrated higher rates of white matter hyperintensities in younger patients with BD. Finally, Altshuler et al. ${ }^{20}$ found no significant differences in the rates of deep white matter hyperintensities although they did find significantly increased periventricular hyperintensities in BD type I compared to BD type II patients or controls. Soares and Mann ${ }^{21}$, on a review study, also mentioned a larger third ventricle, smaller cerebellum and perhaps, smaller temporal lobe, as possible associations. According to these authors, global atrophy was not consistently found, and the association with specific lesions of the limbic system could not be replicated. In a more recent functional neuroimaging review study, Strakowski et al. ${ }^{22}$ suggested there may be reduced prefrontal modulation of subcortical and medial temporal structures within the anterior limbic network that result in dysregulation of mood.

Gondim and Thomas ${ }^{23}$ described a case of MS and episodic hyperlibidinism in which MRI revealed bilateral deep white matter, periventricular and internal capsule lesions in the frontal, parietal and occipital lobes, but not in limbic structures or temporal lobes. Nevertheless, since there are no systematic neuroimaging studies on MS and BD to the present moment, it is difficult to establish a reliable correlation between lesion topography and psychiatric symptoms. An interesting point that should be mentioned is the presence of cortical atrophy in case two. Such finding is more common in secondary progressive MS, and may be related to behavioral and, occasionally, cognitive symptoms ${ }^{24}$.

Although research on the etiopathogenesis of the association between BD and MS is still limited, studies have also focused on a common genetic susceptibility for both conditions. The Human Leukocyte Antigen (HLA) system is determined by genes at several loci on the short arm of chromosome 6 which controls the 
immune response by the expression of surface antigens on immunocompetent cells. The HLA system has been implicated in the vulnerability for many diseases with an autoimmune component. Many studies have reported an increased frequency of certain HLA antigens in MS patients ${ }^{25,26}$. Some authors have examined the involvement of preferential HLA genes in patients with comorbid BD and MS. Schiffer et al. ${ }^{27}$ were the first to explore the relation between MS and affective disorders from perspective. They studied 56 patients and noticed an increased frequency of HLA-DR5 and a decreased frequency of HLA-DR1 and HLA-DR4 specificities in bipolar MS patients with a family history of affective disorder. More recently, Bozikas et al. ${ }^{28}$ examined this possible association based on the HLA family study of a woman with both BD and MS, and family history of BD. In this study, HLA-DR2 haplotype seemed to be a possible susceptibility locus for BD. Although this genetic association needs further investigation, these studies support the hypothesis that genes very close to the HLA region on chromosome 6 may constitute one of the elements in the multifactorial etiology of BD and MS. The investigation of other genetic polymorphisms, notably those related to neurotransmitter circuits such as the serotonin transporter gene, seem to be promising in the study of the susceptibility for both conditions ${ }^{29,30}$.

In summary, although there are many hypotheses on the etiology of the association of BD and MS, more studies focusing on this specific relation are still necessary to establish definitive conclusions.

\section{REFERENCES}

1. Feinstein A. Multiple sclerosis, disease modifying treatments and depression. Mult Scler 2000;6:342-348.

2. Belmaker RH. Bipolar disorder. N Engl J Med 2004;351:476-486.

3. Garland EJ, Zis AP. Multiple sclerosis and affective disorders. Can J Psychiatry 1991;36:112-117.

4. Schiffer RB, Wineman NM, Weitkamp LR. Association between bipolar affective disorder and multiple sclerosis. Am J Psychiatry 1986;143:94-95.

5. Joffe RT, Lippert GP, Gray TA, Sawa G, Horvath Z. Personal and family history of affective illness in patients with multiple sclerosis. J Affective Disord 1987;12:63-65.

6. Edwards LJ, Constantinescu CS. A prospective study of conditions associated with multiple sclerosis in a cohort of 658 consecutive outpatients attending a multiple sclerosis clinic. Mult Scler. 2004;10:575-581.
7. Hutchinson M, Starck J, Buckley P. Bipolar affective disorder prior to the onset of multiple sclerosis. Acta Neurol Scan 1993;88:388-393.

8. Ashgar-Ali A, Taber KH, Hurley RA, Hayman LA. Pure neuropsychiatric presentation of multiple sclerosis. Am J Psychiatry 2004;161:226-231.

9. Jongen PJ. Psychiatric onset of multiple sclerosis. J Neurol Sci 2006; 245:59-62.

10. Lewis DA, Smith RE. Steroid induced psychiatric syndromes: a report of 14 cases and a review of the literature. J Affect Disord 1983;5:319-332.

11. Warrington TP, Bostwick JM. Psychiatric adverse effects of corticosteroids. Mayo Clin Proc 2006;8:1361-1367.

12. Bolanos SH, Khan DA, Hanczyc M, Bauer MS, Dhanani N, Brown ES. Assessment of mood states in patients receiving long-term corticosteroid therapy and in controls with patient-rated and clinician-rated scales. Ann Allergy Asthma Immunol 2004;92:500-505.

13. Ling MHM, Perry PJ, Tsuang MT. Side effects of corticosteroid therapy. Arch Gen Psychiatry 1981;38:471-477.

14. Minden SL, Orav J, Schildkraut JJ. Hypomanic reactions to ACTH and prednisone treatment for multiple sclerosis. Neurology. 1988;38:1631-1634.

15. Lana-Peixoto MA, Teixeira AL, Haase, VG. Interferon beta-1a-induced depression and suicidal ideation in multiple sclerosis. Arq Neuropsiquiatr 2002;60:721-724.

16. Borras C, Rio J, Porcel J, Barrios M, Tintore M, Montalben X. Emotional state of patients with relapsing-remitting MS treated with interferon beta-1b. Neurology 1999;52:1636-1639.

17. Sheline Y. Neuroimaging studies of mood disorder effects on the brain. Biol Psychiatry 2003;54:338-352.

18. McDonald WM, Krishnan KR, Doraiswamy PM, Blazer DG. Occurrence of subcortical hyperintensities in elderly subjects with mania. Psychiatry Res 1991;40:211-220.

19. Dupont RM, Jernigan TL, Heindel H, et al. Magnetic resonance imaging and mood disorders: localization of white matter and other subcortical abnormalities. Arch Gen Psychiatry 1995;52:747-755.

20. Altshuler LL, Curran JG, Hauser P, Mintz J, Denicoff K, Post R. T2 hyperintensities in bipolar disorder: magnetic resonance imaging comparison and literature meta-analysis. Am J Psychiatry 1995;152:1139-1144.

21. Soares JC, Mann JJ. The anatomy of mood disorders: review of structural neuroimaging studies. Biol Psychiatry 1997;41:86-106.

22. Strakowsky SM, DelBello MP, Adler CM. The functional neuroanatomy of bipolar disorder: a review of neuroimaging findings. Mol Psychiatry 2005;10:105-116.

23. Gondim FAA, Thomas FP. Episodic hyperlibidinism in multiple sclerosis. Mult Scler 2001;7:67:70.

24. Morgen K, Sammer G, Courtney SM, et al. Evidence for a direct association between cortical atrophy and cognitive impairment in relapsingremitting MS. Neuroimage 2006;30:891-898.

25. Batchelor JR, Compston A, McDonald WI. The significance of the association between HLA and multiple sclerosis. Br Med Bull 1978;34:279-284.

26. Ebers GC, Paty DW, Stiller CR, et. al. HLA-typing in multiple sclerosis sibling pairs. Lancet 1983;2:88-90.

27. Schiffer RB, Weitkamp LR, Wineman NM, Guttormsen S. Multiple sclerosis and affective disorder: family history, sex and HLA-DR antigens. Arch Neurol 1988;45:1345-1348.

28. Bozikas VP, Anagnostouli MC, Petrikis P, et al. Familial bipolar disorder and multiple sclerosis: a three-generation HLA family study. Prog Neuropsychopharmacol Biol Psychiatry. 2003;27:835-839.

29. Oliveira JRM, Otto PA, Vallada H, et al. Analysis of a novel functional polymorphism within the promoter region of the serotonin transporter gene (5-HTT) in Brazilian patients affected by bipolar disorder and schizophrenia. Am J Med Genet (Neuropsychiatr Genet) 1998;81:225-227.

30. Mansour HA, Talkowski ME, Wood J, et. al. Serotonin gene polymorphisms and bipolar I disorder: focus on the serotonin transporter. Ann Med 2005;37:590-602. 